\title{
Will any dental implant do?
}

\author{
Michael R. Norton ${ }^{1}$
}

\section{Key points}

Implant surfaces can be contaminated with organic and metallic impurities, which might impact

upon quality of osseointegration and risks for peri-implantitis.
It is neither appropriate nor possible to extrapolate data from one implant brand to another.
Due to the exponential growth in the number of implant brands and types available, there is an increasing need for a central UK dental implant registry.

\begin{abstract}
Dental implant treatment is a well-documented technology, but sadly with the passage of time, the vast majority of dental implants sold on the market today have little of their own documentation. All implants are not the same and the consequences of 'look-alike' implants relying on the documentation of others may be far-reaching. This opinion piece highlights concerns identified in the literature and exposes problems that are already occurring in reality.
\end{abstract}

We have come a long way in implant dentistry over the last 30 years. In 1982, the Toronto conference opened the eyes of our North American colleagues to a whole new world, with the introduction of the osseointegrated Brånemark implant. At that time, Nobelpharma (as it was then) had an almost total monopoly, insisting that only their implant had the necessary long-term documentation and clinical evidence to ensure clinicians that these implants could and would last for over 15 years in function, as demonstrated in a published article by Adell et al. in the International Journal of Oral Surgery. ${ }^{1}$

Against this background, two new implant systems from Straumann and the then Astra Meditec were well on their way to commercialisation, having also spent many years in the research and development arena. The rest, as they say, is history; to this day, it is notable that these three implant manufacturers, now Nobel Biocare, Dentsply Sirona (Astra) and Straumann, remain the world leaders in the field and their implants are still considered the three premium brands,

'Norton Implants Ltd, 104 Harley Street, London, W1G 7JD, UK.

Correspondence to: Michael R Norton

Email: drnorton@nortonimplants.com

Accepted 21 January 2020

https://doi.org/10.1038/s41415-020-1302-7 although it is of interest that the Branemark implant itself is no longer part of that cadre. It is, perhaps, therefore no surprise that one can pick up a copy of the $B D J$ and read in an advert that a new implant can 'osseointegrate as well as Nobel, Straumann and Astra'!

The question is whether we should be concerned that such statements, or those announcing 'the new implant system on the block', are adding to the growing belief that all implants are the same. The correct question then is: are all implants the same? As a member of the Advisory Board of the Clean Implant Foundation, along with great names like Prof Tomas Albrektsson, we challenge this question by seeking to confirm that, at the very least, all implant surfaces are delivered with a comparable cleanliness and purity of chemistry. Sadly, the answer is that all implants are far from the same. In a recent publication on the cleanliness of different oral implant systems, Duddeck et al. identified that, compared to the three premium brand implants identified above, three comparable look-alike implants showed, within the scope of the analysis, that the look-alike implants had surfaces contaminated with impurities such as organic residues and unintended metal particles such as iron and aluminium. They concluded that, compared to the ultraclean premium brand implant surfaces, these implants were far from clean and they also commented that they had little or no documentation. ${ }^{2}$ It is not unreasonable to assume that such contaminants will impact upon the quality of osseointegration and the vulnerability to peri-implant inflammation.

In my capacity as a dento-legal expert providing reports on implant cases that have gone wrong, it has not escaped my notice that many of these cases utilise cheap, lookalike implants from unknown companies. It is troubling on a number of levels. First and foremost, these implants typically get their FDA approval or CE mark on the back of the so-called $510(\mathrm{k})$ or prior precedent process. That is, that if it looks like a titanium screw and it smells like a titanium screw, it is probably a dental implant that works much like every other. In other words, these implants have required little or no documentation of their own, rather relying on the documentation of the three premium brands for their evidence base. This is a flawed approach and the regulators must change the rules requiring every new implant to have at least three years of clinical documentation, as well as a thorough surface analysis similar to that undertaken by Duddeck et al. ${ }^{2}$. Perhaps the new EU Medical Devices Regulation (MDR) due to come into effect on 26 May this year will go a long way to address this problem, since it is a much more demanding evidence-based process than the Medical Devices Directive (MDD) 
regulations which it is due to replace. Secondly, as many colleagues will attest, it is often the case that when problems occur with these implants, they can be hard or even impossible to identify. This is because, typically, patients have not been advised of the brand and the providing clinician is no longer available to provide that information or, if they are, then sometimes they are not even in possession of the knowledge to answer the question. In a recent dento-legal case, I was confronted with a total absence of clinical records with regards to the implant surgery and the providing clinician was unable to identify which implants he had placed, as he placed many different brands of implant and could not remember or identify what implants they were in this particular case! Certainly, lawyers and the courts are taking an increasing interest in the brand of implant used and whether it has the appropriate documentation to support its use.

Worse still, many of the minor manufacturers go out of business, leaving the patient in a compromised state with an implant that cannot be restored or treated as required. Such implants ultimately end up having to be removed, which is a very traumatic and destructive process and not what patients should be exposed to.

Of course, one easy solution to part of this problem would be a dental implant registry.
I recall in the early years as President of the Association of Dental Implantology, and more recently in my role as President of the Academy of Osseointegration, that debates were held about whether it was possible to instigate such a registry. Here in the UK for a time we established the Association of Dental Implant Auxiliaries (ADIA), an online registry run by the ADI. This still exists in the form of a personal logbook, but it is far from a central registry for all dental implants placed in the UK. By contrast, in the orthopaedic world, we have the National Joint Registry (NJR), set up by the Department of Health and Welsh Government in 2002 to collect information on all hip, knee, ankle, elbow and shoulder replacement operations. This was set up to monitor the performance of joint replacement implants and the effectiveness of different types of surgery, improving clinical standards and benefiting patients, clinicians and the orthopaedic sector as a whole. Furthermore, in 2016 in response to the PIP breast implant scandal and the increasingly uncontrolled provision of cosmetic procedures such as Botox injections, the Breast and Cosmetic Implant Registry was also set up in England and Scotland by both the NHS and private providers. I believe it is now time for the government to do the same for dental implants, which are rapidly becoming one of the leading causes of dento-legal litigation in the UK due to the patient costs incurred with out-ofpocket funding, often requiring patients to take loans or even re-mortgage their homes. The profession undoubtedly has a big responsibility to these patients to ideally ensure that things don't go wrong at the front end, but also to ensure that when things do go wrong, as they will on occasion, as much information is available as possible to all parties concerned.

Thus, to all those who have an established interest in placing implants or for those just embarking on this area of dentistry, I say choose your implant wisely. Seek evidence of documentation for your implant in one of the mainstream peer-review dental implant journals and make sure you keep contemporaneous records of the implants used. All companies provide stickers; use them in your clinical records and give one to the patient too, so that they have a record of the manufacturer, brand, dimensions and lot number. Little things like this can make a big difference!

\section{References}

1. Adell R, Lekholm U, Rockler B, Brånemark PI. A 15-year study of osseointegrated implants in the treatment of the edentulous jaw. Int J Oral Surg 1981; 10: 387-416.

2. Duddeck D U, Albrektsson T, Wennerberg A, Larsson C, Beuer F. On the Cleanliness of Different Oral Implant Systems: A Pilot Study. J Clin Med 2019; DOI: 10.3390/ jcm8091280. 